Org Lett. 2019 April 19; 21(8): 2855-2858. doi:10.1021/acs.orglett.9b00858.

\title{
Photoinitiated Cascade for Rapid Access to Pyrroloquinazolinone Core of Vasicinone, Luotonins and Related Alkaloids.
}

\author{
D. Sai Reddy, Andrei G. Kutateladze \\ Department of Chemistry and Biochemistry, University of Denver, Denver, CO 80208
}

\begin{abstract}
Furylimines of aromatic o-nitro aldehydes undergo a photoinduced cascade transformation offering rapid atom- and step-economical access to complex polyheterocyclic scaffolds possessing a privileged pyrroloquinazolinone core.
\end{abstract}

\section{Graphical Abstract}

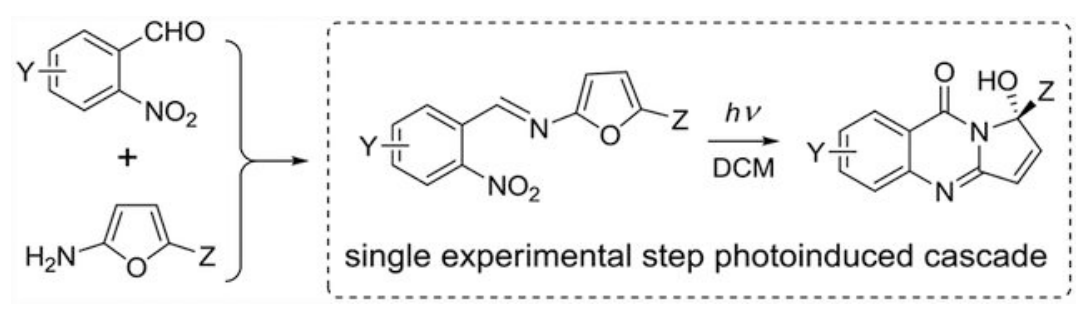

Recent renaissance in photoredox catalysis - and synthetic photochemistry in general speaks volumes about the ability of photoinduced reactions to access complex molecular architectures in a minimal number of steps. ${ }^{1}$ Combining more than one step in a photoinitiated cascade improves step-normalized growth of complexity, while simplifying and streamlining experimental procedures. ${ }^{2}$ In our own work we demonstrated that extended polyheterocyclic scaffolds, rivaling the complexity indices ${ }^{3}$ of complex natural products, could be assembled in 2-4 experimentally simple steps from ubiquitous chemical feedstock utilizing a photochemical cascade as the key step. ${ }^{4}$

In our search for new photoinduced cascade transformations to access complex heterocycles, we realized that some well-known photoinduced rearrangements are absent from the toolbox of synthetic chemistry. One of these reactions - a photoinduced hydrogen atom transfer from the benzylic $\mathrm{sp}^{3}$ carbon in $o$-nitrobenzyl systems - is widely used in photoremovable protecting groups (PPG) chemistry, but rarely used in synthesis, with a notable exception of

\footnotetext{
*Corresponding Author: akutatel@du.edu.

Supporting Information

The Supporting Information is available free of charge on the ACS Publications website.

Experimental procedures, characterization data, ${ }^{1} \mathrm{H}$ and ${ }^{13} \mathrm{CNMR}$ spectra for all compounds, computational details and calculated NMR chemical shifts and constants (PDF)

The authors declare no competing financial interest.
} 
photochemical synthesis of indazolones recently reported by Kurth and co-workers. ${ }^{5}$

Another variation on this theme is the well-known intramolecular redox disproportionation in $o$-nitrobenzaldehyde, which is initiated by hydrogen atom abstraction from the $\mathrm{sp}^{2}$ carbon, resulting in the formation of o-nitrosobenzoic acid. This reaction has been widely used for UV actinometry in the 280-410nm range of UV spectrum. ${ }^{6}$

We note that nitroso compounds exhibit a wealth of synthetically useful reactivity, from aldol-like condensations to nitroso Diels-Alder reactions yielding cyclic hydroxyla-mines, ${ }^{7}$ which are often reduced or undergo $\mathrm{N}-\mathrm{O}$ bond scission either photochemically or under thermal activation. In this work, we developed a photoinduced cascade which involves a photochemical generation of transient aryl nitroso species, its intramolecular Diels-Alder reaction with furan moiety to furnish oxazabicyclo[2.2.1] heptane core possessing the labile $\mathrm{N}-\mathrm{O}$ moiety with subsequent rearrangement into the target pyrroloquinazolinone in a single step. Pyrrolo- or pyrrolidino-quinazolinone core is a prominent feature in many biologically active natural products, including alkaloids vasicinone, ${ }^{8}$ tryptanthrin, ${ }^{9}$ and luotonins ${ }^{10}$ shown in Figure 1.

A number of ground state reactions to access alkaloids containing pyrroloquinazolinone core are known. For example, synthesis of luotonins via a radical cascade; ${ }^{11}$ synthesis of vasicinone and related heterocycles from (i) o-azidobenzoic acid derivatives by reductive cyclization ${ }^{12}$ or (ii) condensation of anthranylamide and acetoxysuccinic anhydride ${ }^{13}$ or other derivatives of succinic acid; ${ }^{14}$ access to quinazolinone core in the luotonin synthesis via reaction of anthranylamide with acyl chlorides ${ }^{15}$ or with quinolincarboxaldehyde. ${ }^{16}$ Several of these ground state syntheses of pyrroloquinazolinones are nicely summarized in ref. ${ }^{17}$

Our photoinduced cascade offers a much milder option for construction of pyrroloquinazolinone cores. Scheme 1 illustrates the typical reaction of methyl 5aminofuran-2-carboxylate 2a and 3-nitropyridine-2-carbaldehyde 1d providing expeditious access to pyrrolo-aza-quinazolinone framework. Imines are formed under standard conditions. The subsequent photoinduced cascade is carried out in dichloromethane (DCM), Scheme 1.

Overall, this approach gives rapid access to complex polyheterocyclic scaffolds in an experimentally simple atom-and step-economical way from readily available starting materials. In this context, not unimportant is the fact that the recent developments in sustainable chemistry point to a number of furan-based semi-products as a viable bio-massderived chemical feedstock. ${ }^{18}$

The simplicity of the experimental procedure is a prominent feature of this short photoassisted synthetic sequence. As many aromatic $o$-nitro aldehydes and acceptorsubstituted furanamines are readily available from commercial sources, we tested the scope of this reaction sequence and found that the procedure is broadly applicable. Examples with isolated yields are presented in Table 1 below. Notice that hemiaminals $\mathbf{4}$ are racemic.

Structures of pyrroloquinazolinones $4 \mathbf{a a}, \mathbf{4 b a}$, and $\mathbf{4 a b}$ were established with $\mathrm{x}$-ray crystallography. The rest of the products were characterized by solution NMR, with the 
DU8+ computations ${ }^{19}$ of NMR chemical shifts and spin-spin coupling constants supporting the structure assignment. For the details of these computations and rmsd values matching ${ }^{1} \mathrm{H},{ }^{13} \mathrm{C}$ NMR chemical shifts and proton spin coupling constants see Supporting Information.

Our mechanistic rationale for this cascade is shown in Scheme 2. It involves intramolecular hydrogen atom abstraction by the ortho-nitro group in benzaldimine 3aa followed by oxygen transfer via cycloaddition/fragmentation. This leads to the formation of nitroso amide $\mathrm{C}$, which undergoes the intramolecular hetero Diels Alder reaction to form D. Cyclic hydroxylamine D undergoes homolytic fragmentation with the N,O-diradical $\mathrm{E}$ being reduced via $\mathrm{H}$-abstraction, presumably from the solvent $(\mathrm{CH} 2 \mathrm{Cl} 2)$. The dehydrated open form $\mathrm{G}$ of the resulting hemiacetal $\mathrm{F}$ then spontaneously cyclizes into the hemi-aminal product 4aa. Since the vicinal protons of the double-bond in the open form $\mathrm{G}$ are expected to have very different chemical shifts and spin-spin coupling constants from 4aa, we could confidently corroborate that there is no open form $\mathrm{E}$ in the NMR spectrum of the reaction mixture.

NMR reaction following reveals intermittent appearance of the NH proton belonging to nitroso amide $\mathrm{C}$. The Diels-Alder intermediate $\mathrm{D}$ was not isolated, although very small olefinic peaks with $J=5.9 \mathrm{~Hz}$ observed in the reaction mixture are consistent with the heterobicyclo[2.2.1] heptene $\mathrm{CH}=\mathrm{CH}$ moiety and may belong to this transient. ${ }^{20}$

Utilization of o-nitrobenzaldimine of 5-cyanofuranamine (3ae) offers an atom- and stepeconomical pathway to the carba-analog of luotonin B (7) as shown in Scheme 3. The primary product of the photoinduced cascade in this case is cyanohydrin 4ae which is expected to lose $\mathrm{HCN}$ and act as dienophile $\mathbf{5}^{21}$ in the postphotochemical step, i.e. DielsAlder reaction with isobenzofuran (readily available as described before ${ }^{22}$ ). After this experimentally simple photoinitiated one-pot sequence, the reaction mixture in acetic acid is treated with $\mathrm{Zn}$ powder.

This last step accomplishes two goals: aromatization of the oxabenzobicyclo[2.2.1] heptane moiety in $\mathbf{6}$ and selective reduction of the butyrolactam moiety into hemiaminal, furnishing the carba-analog of luotonin B (7).

In conclusion, we developed a new experimentally simple atom- and step-economical approach to diverse pyrroloquinazolinones via a photoinitiated cascade starting from a readily available feedstock. The cascade is initiated by the synthetically underutilized photoinduced benzylic hydrogen transfer in o-nitroaromatics which sets up [4+2] cycloaddition of the transient nitroso arenes. As a diverse library of imines $3 \mathbf{x e}$ could be assembled in a modular fashion from various (hetero)aromatic nitroaldehydes and furanamines, our approach allows for rapid access to complex polyheterocycles in a minimal number of steps. Experimentally simple postphotochemical transformations of the primary photoproducts allow for further growth of the diversity and complexity of the target heterocyclic scaffolds. 


\section{Supplementary Material}

Refer to Web version on PubMed Central for supplementary material.

\section{ACKNOWLEDGMENT}

This work is supported by the NIH (GM093930)

\section{REFERENCES}

(1). for reviews see:(a)Kärkäs MD; Porco JA Jr.; and Stephenson CR J. Chem. Rev, 2016, 116, 9683. (b)Staveness D; Bosque I; Stephenson CR J. Acc. Chem. Res 2016, 49, 2295.(c)Hoffmann N; Chem. Rev, 2008, 108, 1052. [PubMed: 18302419]

(2). recent examples:(a)He L; Wang X; Wu X; Meng Z; Peng X; Liu X-Y; Qin Y Org. Lett 2019, 21, 252. [PubMed: 30560668] (b)Wang L; Ma T; Qiao M; Wu Q; Shi D; Xiao W Synthesis 2019, 51, 522.(c)Qu C; Wu Z; Li W; Du H; Zhu C Adv. Synth. Catal 2019, 359, 1672.(d)Zech A; Thorsten BJ Org. Chem 2018, 83, 3069.(e)Wozniak L; Magagnano G; Melchiorre P Angew Chem. Int. Ed 2018, 57, 1068.(f)Buendia J; Chang Z; Eijsberg H; Guillot R; Frongia A; Secci F; Xie J; Robin S; Boddaert T; Aitken DJ Angew. Chem. Int. Ed 2018, 57, 6592.(g)Wu K; Du Y; Wei Z; Wang T Chem. Commun 2018, 54, 7443.(h)Garbarino S; Ravelli D; Protti S; Basso A Angew. Chem. int. Ed 2016, 55, 15476.(i)Liu X; Ye X; Bures F; Liu H; Jiang Z Angew. Chem. Int. Ed 2015, 54, 11443.(j)Mohamed RK; Modal S; Jorner K; Delgado TF; Lobodin VV; Ottosson H; Alabugin IV J. Am. Chem. Soc 2015, 137, 15441. [PubMed: 26536479] (k)Tan H; Zheng C; Liu Z; Wang DZ Org. Lett 2011, 13, 2192. [PubMed: 21446662] (1)Tucker JW; Nguyen JD; Narayanam JMR; Krabbe SW; Stephenson CR J. Chem. Commun 2010, 46, 4985.

(3). for a recent paper on molecular complexity and an overview of molecular complexity indices from Bertz's index to the latest ones, seeBottcher TJ. of Chem. Inf. Model 2016, 56, 462 and references therein. [PubMed: 26857537]

(4). (a)Kuznetsov DM; Kutateladze AG J. Am. Chem. Soc, 2017, 139, 16584. [PubMed: 29053265] (b)Cronk WC; Mukhina OA; Kutateladze AG Org. Lett, 2016, 18, 3750. [PubMed: 27456284] (c)Kuznetsov DM; Mukhina OA; Kutateladze AG Angew. Chem. Int Ed, 2016, 55, 6988. (d)Mukhina OA; Kutateladze AG J. Am. Chem. Soc, 2016, 138, 2110. [PubMed: 26866604] (e)Kumar NNB; Kutateladze AG Org. Lett, 2016, 18, 460. [PubMed: 26760049] (f)Mukhina OA; Kuznetsov DM; Cowger TM; Kutateladze AG Angew. Chem. Int. Ed, 2015, 54, 11516.(g)Kumar NNB; Kuznetsov DM; Kutateladze AG Org. Lett, 2015, 17, 438. [PubMed: 25587772] (h)Mukhina OA; Kumar NNB; Cowger TM; Kutateladze AG J. Org. Chem, 2014, 79, 10956. [PubMed: 25370821] (i)Mukhina OA; Kumar NNB; Arisco TM; Valiulin RA; Metzel GA; Kutateladze AG Angew. Chem. Int. Ed, 2011, 50, 9423.

(5). Zhu JS; Kraemer N; Li CJ; Haddadin MJ; Kurth MJ J. Org. Chem 2018, 83, 15493. [PubMed: 30468072]

(6). (a)see Allen JM; Allen SK; Baertschi SW J. Pharm. Biomed. Anal 2000, 24167 and references therein. [PubMed: 11130196] (b)Kuhn HJ; Braslavsky SE; Schmidt R Pure Appl. Chem 2004, $76,2105$.

(7). (a)Yamamoto H; Kawasaki M Bull. Chem. Soc. Jpn 2007, 80, 595.(b)Yamamoto Y; Yamamoto H Eur. J. Org. Chem 2006, 2031.(c)Vogt PF; Miller MJ Tetrahedron 1998, 54, 1317.(d)Yamamoto H; Momiyama N Chem. Commun 2005, 3514.(e)Vogt PF; Miller MJ Tetrahedron 1998, 54, 1317.(f)Waldmann H Synthesis 1994, 535.

(8). (a)Amin AH; Mehta DR Nature 1959, 183, 1317.(b)Mehta DR; Naravane JSR; Desai MJ Org. Chem 1963, 28, 445.(c)Jain MP; Koul SK; Dhar KL; Atal CK Phytochemistry 1980, 19, 1880.

(9). for recent publications on tryptanthrin, which was known for more than 100 years, seeGarcellano RC; Moinuddin SGA; Young RP; Zhou M; Bowden ME; Renslow RS; Yesiltepe Y; Thomas DG; Colby SM; Chouinard CD; Nagy G; Attah IK; Ibrahim YM; Ma R; Franzblau SG; Lewis NG; Aguinaldo AM; Cort JR J. Nat. Prod, 2019, 82, 440, and references therein. [PubMed: 30295480]

(10). (a)Ma Z-Z; Hano Y; Nomura T; Chen Y-J Heterocycles 1997, 46, 541.(b)Ma Z-Z; Hano Y; Nomura T; Chen Y-J Heterocycles 1999, 51, 1883.(c)Ma Z-Z; Hano Y; Nomura T; Chen Y-J 
Tennen Yuki Ka-gobutsu ToronkaiKoen Yoshishu 1999, 41, 547;Chem. Abstr 2000, 132, 234276. (d)Ma Z-Z; Hano Y; Nomura T; Chen Y-J Phytochemistry 2000, 53, 1075. [PubMed: 10820833]

(11). Beaume A; Courillon C; Derat E; Malacria M Chem. Eur. J 2008, 14, 1238. [PubMed: 18046682]

(12). Kamal A; Ramana KV; Rao MV J. Org. Chem 2001, 66, 997. [PubMed: 11430123]

(13). Mhaske S,B; Argade NP J. Org. Chem 2001, 66, 9038. [PubMed: 11749642]

(14). Shemchuk LA; Chernykh VP; Krys'kiv OS Russ. J. Org. Chem, 2006, 42, 382.

(15). Mhaske SB,; Argade NP J. Org. Chem 2004, 69, 4566.

(16). Chavan SP; Sivappa R Tetrahedron 2004, 60, 9931.

(17). see Table 4 inMhaske SB; Argade NP Tetrahedron, 2006, 62, 9787.

(18). Kucherov FA; Romashov LV; Galkin KI; Ananikov VP ACS Sustainable Chem. Eng, 2018, 6, 8064.

(19). for method development and applications of $D U 8+$ see(a)Kutateladze AG; Kuznetsov DM; Beloglazkina AA; Holt TJ J. Org. Chem, 2018, 83, 8341. [PubMed: 29912559] (b)Kutateladze AG; Kuznetsov DM J. Org. Chem, 2017, 82, 10795. [PubMed: 28886245] (c)Kutateladze AG; Reddy DS J. Org. Chem, 2017, 82, 3368. [PubMed: 28339201] (d)Kutateladze AG; Mukhina OA J. Org. Chem, 2015, 80, 10838. [PubMed: 26414291] (e)Kutateladze AG; Mukhina OA J. Org. Chem, 2015, 80, 5218. [PubMed: 25885091] (f)Kutateladze AG; Mukhina OA J. Org. Chem, 2014, 79, 8397. [PubMed: 25158224]

(20). this type of transient nitroso Diels-Alder intermediates was postulated before:(a)Wanner MJ; Koomen G-JJ Chem. Soc., Perkin Trans 1, 2001, 1908.(b)Butin AV; Stroganova TA; Lodina IV; Krapivin GD Tetrahedron Lett 2001, 42, 2031.

(21). quinazolinone 5 is alternatively accessible through ground-state reactions, for example, microwave-assisted condensation of anthranilamide with maleic anhydride in acetic anhydride in the presence of AcONa seeShemchuk LA; Chernykh VP; Krys'kiv OS Russ. J. Org. Chem 2006, 42,382. However, the photochemical cascade shown in Scheme 3 allows for accessing the DielsAlder product 6 in a one-pot fashion under exceptionally mild conditions in dichloromethane, which could be advantageous for the cases when the targeted quinazolinone product possesses sensitive functional groups as desired substituents.

(22). Peters MK; Herges R Beilstein. J. Org. Chem 2017, 13, 2659. [PubMed: 30018664]

Org Lett. Author manuscript; available in PMC 2020 April 19. 
<smiles>O=c1c2ccccc2nc2n1CCC2O</smiles>

vasicinone<smiles>O=C1c2ccccc2-n2c1nc1ccccc1c2=O</smiles>

tryptanthrin<smiles>O=c1c2ccccc2nc2n1C(O)c1cc3ccccc3nc1-2</smiles>

luotonin B

Figure 1.

Vasicinone, tryptanthrin, and luotonin B. 
<smiles>O=Cc1ncccc1[N+](=O)[O-]</smiles>

1d<smiles>COC(=O)c1ccc(N)o1</smiles>

2a $\underset{\text { toluene }}{\stackrel{\text { cat } \mathrm{AcOH}}{\longrightarrow}}$

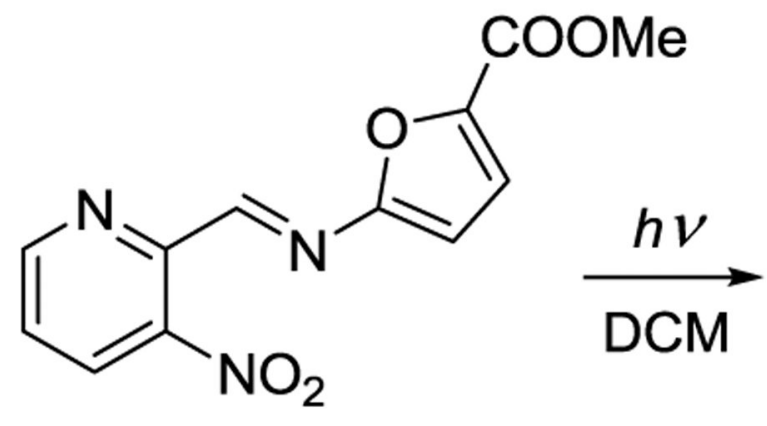

3da

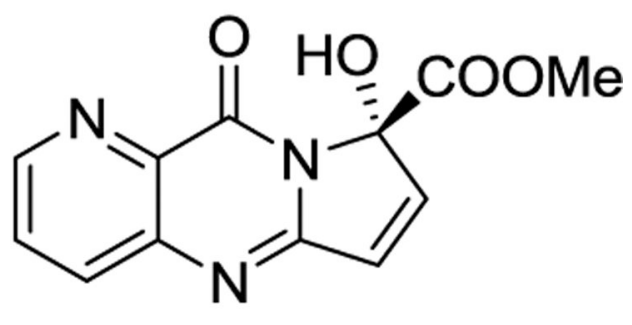

4da

Scheme 1.

A typical furylimine formation and subsequent photoinduced cascade furnishing a fused pyrimidone. 


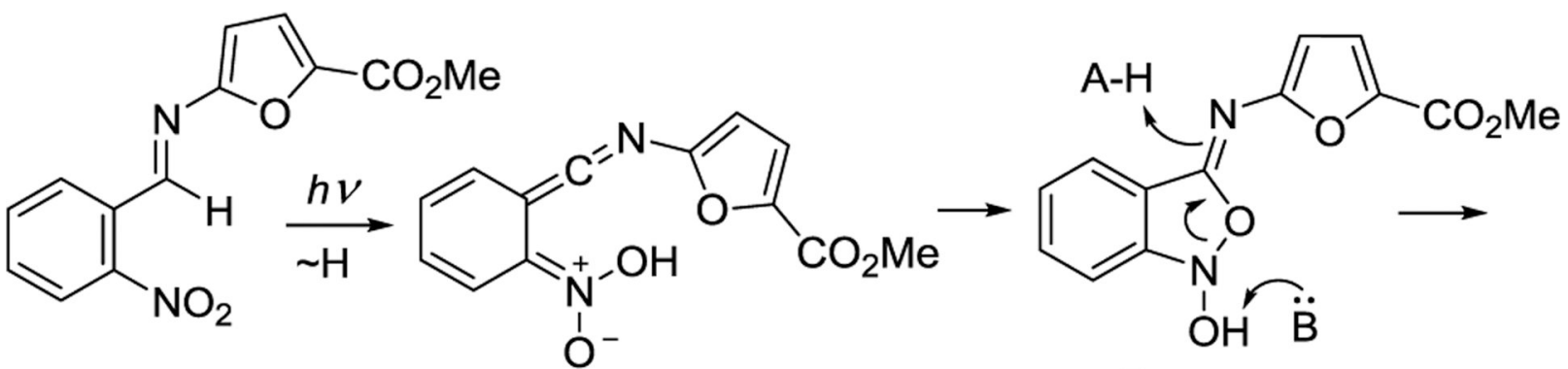

3aa

A

B<smiles>COC(=O)c1ccc(NC(=O)c2ccccc2N=O)o1</smiles><smiles>COC(=O)C12C=CC3(NC(=O)c4ccccc4N1O3)O2</smiles><smiles>COC(=O)C1(O)C=CC2(NC(=O)c3ccccc3N2)O1</smiles>

C<smiles>COC(=O)C(O)(/C=C\C1(O)NC(=O)c2ccccc2N1)C(=O)F</smiles><smiles></smiles><smiles>COC(=O)[C@]1(O)C=Cc2nc3ccccc3c(=O)n21</smiles>

Scheme 2.

A plausible mechanistic rationale for the photoinduced cascade 3aa $\rightarrow$ 4aa. 
<smiles>N#Cc1ccc(/N=C/c2ccccc2[N+](=O)[O-])o1</smiles><smiles>N#C[C@]1(O)C=Cc2nc3ccccc3c(=O)n21</smiles>

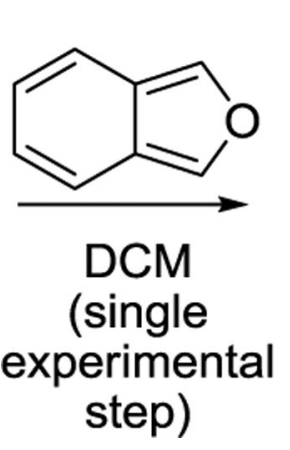

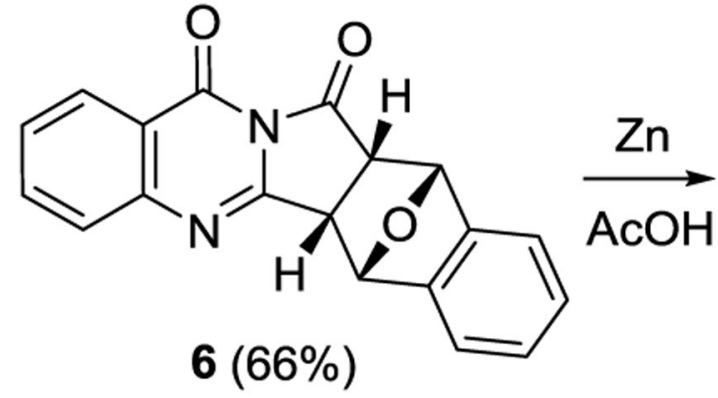<smiles>O=c1c2ccccc2nc2n1C(O)c1cc3ccccc3cc1-2</smiles>

Scheme 3.

Atom- and step-economical synthesis of the carba-analog of luotonin B (7). 
Table 1.

Pyrroloquinazolinone Products and Isolated Yields.

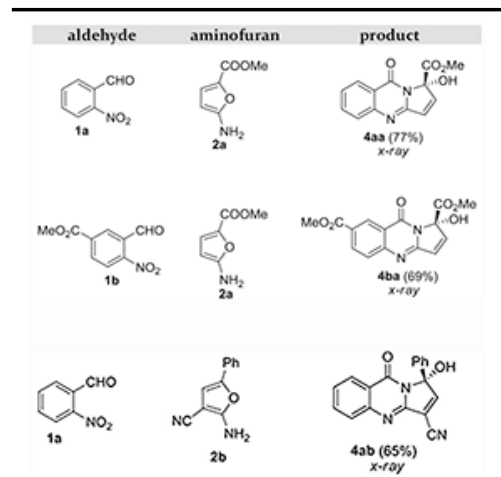

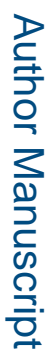
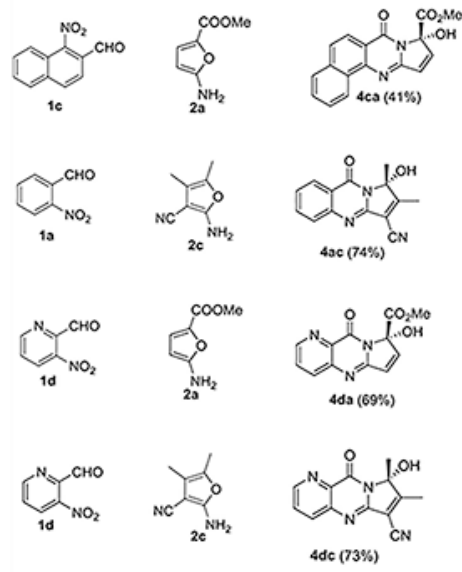

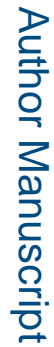
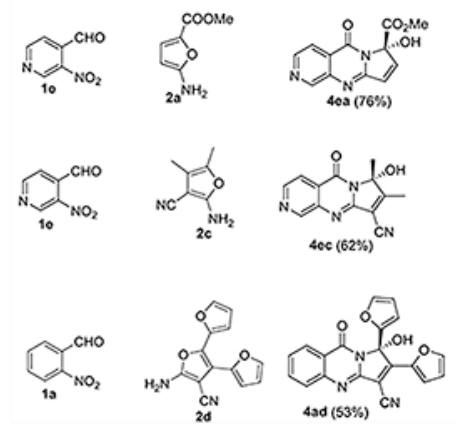

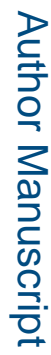

Org Lett. Author manuscript; available in PMC 2020 April 19. 